\title{
NOTAS DE JURISPRUDENCIA
}

\section{Tribunal Constitucional (*)}

\begin{abstract}
SUMARIO: I. CONSTITUCIÓN. A. Fuerza normativa. B. Interpretación. II. DERECHOS Y LIBERTADES. A. Derechos fundamentales y libertades públicas. B. Derechos y deberes de los ciudadanos. C. Principios rectores de la política social y económica. D. Garantía y suspensión de estos derechos. III. PRINCIPIOS JURÍDICOS BÁSICOS. IV. INSTITUCIONES DEL ESTADO. A. La Corona. B. Las Cortes Generales. C. El Tribunal Constitucional. D. La Administración Pública. E. El Poder Judicial. V. FUENTES. VI. ORGANIZACIÓN TERRITORIAL DEL ESTADO. A. Comunidades Autónomas. A.1. Autonomía. B.2. Competencias. B. Corporaciones Locales. A.1. Autonomía B.2. Competencias. VII. ECONOMÍA Y HACIENDA. A. Principios generales. B. Presupuestos. C. Organización territorial. D. Tribunal de Cuentas.
\end{abstract}

\section{DERECHOS Y LIBERTADES}

\section{A. Derechos fundamentales y libertades públicas.}

1. Sentencia 125/2003, de 19 de junio (BOE de 17 de julio). Ponente: Conde Martín de Hijas (Cuestión de inconstitucionalidad).

Preceptos constitucionales: 14.

otros:

Objeto: Regla 5 de la DA Décima de la L 30/1981, de 7 de julio, reguladora de las formas de matrimonio y del procedimiento a seguir en las causas de nulidad, separación y divorcio.

Materias: Principio de igualdad ante la Ley: pérdida de pensión de viudeda por convivencia marital.

\footnotetext{
(*) Subsección preparada por FRANCISCO ESCRIBANO.
} 
Dos son los supuestos de hecho que se plantean. Por una parte, la de quienes obtienen una pensión de viudedad devengada por quien contrajo un solo matrimonio no anulado, ni afectado por separación o divorcio, en tal caso el viudo o viuda percibirá la pensión incluso si convive more uxorio con otra persona. Por otra, los supuestos de pensión de viudedad devengada por quien contrajo dos o más matrimonios, pues en tal supuesto los cónyuges cuyo matrimonio fue anulado, o sufrieron los efectos del divorcio o separación que obtuvieron dicha clase de pensión, la perderán si pasan a convivir maritalmente con otra persona. A tenor de las consideraciones de la Sala proponente se produce la disparidad de trato por cuanto en ambos casos se reconoce una misma cualidad: preceptores de una pensión, causada por un mismo causante y por el mismo e idéntico motivo (haber contraído matrimonio con aquél). La ley establece la discriminación de la pérdida del derecho a la pensión en un caso, mientras que, por el contrario, no lo contempla en el otro. La norma cuestionada se aplica sólo a los cónyuges supervivientes al causante que se encuentren en los casos de separación o divorcio, pero no a los viudos que convivan con él al tiempo de su muerte; considera el TC que los supuestos planteados por la cuestión se pueden reducir a uno solo, el definido por la condición de viudo conviviente con el causante, siendo ésta la cualidad común que define el término de comparación. A tenor de las precisiones del Tc la cuestión a la que se debe ceñir la Sentencia es sólo la relativa al desigual manejo o aplicación por el legislador ante dos pensiones de viudedad, así procede analizar si el distinto régimen jurídico que en relación a la extinción de la pensión de viudedad se contiene en la cuestionada norma se funda en una diferencia real que justifique la razonabilidad y objetividad del distinto tratamiento jurídico. La constatación de una panorama de desigualdad resulta evidente. Supuesto nacido el derecho a la pensión en situaciones diversas, no parece razonable que éste pueda extinguirse en identidad de situaciones en unos casos, sí y en otros, no. Si la convivencia more uxorio con una persona es perfectamente lícita en el marco de nuestro ordenamiento, de ese hecho lícito no puede seguirse la privación de una pensión de viudedad, sólo en ciertos casos, es decir, en los de pensionistas que al tiempo de obtener el derecho a la pensión estuvieren anulados, separados o divorciados del causante de la misma y vinieren a relacionarse more uxorio con otra persona. El factor de diferenciación no reúne la cualidad de elemento razonable y constitucionalmente exigible para descartar la discriminación ante supuestos de hecho que reciban diferente trato legal, lo que se considera directa vulneración del art. $14 \mathrm{CE}$.

VOTO PARTICULAR (Conde Martín de Hijas, al que se adhieren GarcíaCalvo y Montiel y Rodríguez-Zapata Pérez): Se disiente de la interpretación que se da al punto de partida, es decir, a la Regla 5 de la DA Décima. En ella se da igualdad de trato a amabas situaciones, será la interpretación judicial de la norma la que ha creado la discriminación de trato. El TC ha dado por 
buena esa interpretación que el disidente considera errónea. La desigualdad se produce, además, por la interpretación que se hace no de una ley, sino de dos leyes distintas a supuestos que se consideran iguales. La interpretación y aplicación de la norma adquirirá relevancia constitucional cuando aquélla afecte a derechos fundamentales, ya que de la misma se puede derivar vulneración de principios, como en este caso, de igualdad (STC 39/1992). El TC en su sentencia de la que se discrepa no ha querido entrar en este aspecto de la cuestión, produciéndose por consiguiente la paradoja de que se es más respetuoso con la interpretación judicial de la norma que con la propia norma. Las exigencias del derecho de igualdad imponen el rechazo de una interpretación restrictiva de los supuestos contemplados en la DA Décima conducente a una separación de regímenes. Puesta de manifiesto las diferentes situaciones de desigualdad que la interpretación judicial de la norma provoca, y considerando que el TC debió entrar a analizarlas y, en su caso, a considerar otra diversa, que es la propugnada en el VP, se considera que la cuestión debió ser desestimada.

(Cachón Villar, Jiménez Sánchez y Gay Montalvo): Se parte de la doctrina del TC sobre el principio de igualdad ante la Ley en la Sentencia 144/1988, en su aplicación de ha pertirse, como premisa, de la existencia de situaciones o supuestos de hecho que, desde todos los puntos de vista legítimamente adoptables, sean iguales (SSTC 212/1993; 80/1994; 1/2001). Tal requisito esencial no concurre en el presente caso. Se trata de situaciones de hecho que, respecto del causante de la pensión, se muestran claramente diferentes. Que el legislador haya establecido diversos supuestos de extinción diferenciados para supuestos, asimismo diferentes, de obtención del derecho no puede considerarse vulneración del derecho a la igualdad. La cuestión, en definitiva, no responde a un criterio arbitrario.

\section{B. Derechos y deberes de los ciudadanos.}

1. Sentencia 137/2003, de 3 de julio (BOE de 30 de julio). Ponente: Casas Baamonde (Recurso de inconstitucionalidad).

Preceptos constitucionales: $31.1 ; 86$.

otros:

Objeto: Art. 34 del Real Decreto-Ley 12/1995, de 28 de diciembre, sobre medidas urgentes en materia presupuestaria, tributaria y financiera, mediante el que se modifica el tipo de gravamen del impuesto especial sobre determinados medios de transportes. 
Materias: Justicia tributaria. Decreto-ley. Efectos de las Sentencias del TC.

La modificación en el citado impuesto especial realizada mediante decretoley es injustificada, sin que sea posible apreciar la existencia de una situación de extraordinaria y urgente necesidad que habilitara la reducción de los tipos, dicha medida de forma inexorable incide u supone una afectación al deber de contribuir regulado en el art. 31.1, vedada por el art. 86. Con este modo de modificación normativa se han violado, asimismo, la garantía procedimental prevista en el art. 46 EACan, así como la DA 3aㅡ CE. En todo caso, no se ha producido el trámite de audiencia al Parlamento Canario, según establece la previsión estatutaria. Por lo que se refiere al uso del decreto ley hay que comenzar recordando la doctrina del TC sobre el cumplimiento del requisito de la apreciación de la urgente y extraordinaria necesidad (SSTC 182/1997 y 11/2002): la necesaria conexión entre la facultad legislativa excepcional y la existencia del presupuesto habilitante conduce a que el concepto de extraordinaria y urgente necesidad que se contiene en la Constitución no sea, en modo alguno, una cláusula o expresión vacía de significado dentro de la cual el lógico margen de apreciación política del Gobierno se mueva libremente sin restricción alguna, sino, por el contrario, la constatación de un límite jurídico a la actuación mediante decretos-leyes. Por ello es función propia del TC el aseguramiento de estos límites, la garantía de que en el ejercicio de esta facultad, como de cualquier otra, los poderes se mueven dentro del marco trazado por la Constitución", de modo que el Tribunal Constitucional podrá, en supuestos de uso abusivo o arbitrario, rechazar la definición que los órganos políticos hagan de una situación determinada y, en consecuencia, declarar la inconstitucionalidad de un Decreto-ley por inexistencia del presupuesto habilitante por invasión de las facultades reservadas a las Cortes Generales por la Constitución (STC 11/2002, de 17 de enero, FJ 4). A los efectos de este control será necesario analizar dos elementos: los motivos que hayan sido explicitados de forma razonada (STC 29/1982, FJ 3; STC 111/1983, FJ 5; 182/1997, FJ 3); así como la existencia de una necesaria conexión entre la situación de urgencia definida y la medida concretada adopta para subvenir a la misma (STC 29/1982, FJ 3; 182/1997, FJ 3). El TC admite que la situación de prórroga de los Presupuestos pudieran haber justificado, con carácter general, el decreto-ley, lo que no es óbice para que no pudieran estar justificadas todas y cada una de las normas que lo contienen. No cabe olvidar que, como ya se señaló en el FJ 3 de la STC 182/1997 el control que compete al Tribunal Constitucional en este punto es un control externo, en el sentido de que debe verificar, pero no sustituir, el juicio político o de oportunidad que corresponde al Gobierno y al Congreso de los Diputados en el ejercicio de la función de control parlamentario (art. 86.2 $C E)$; al tiempo convendrá, asimismo, recordar que es preciso valorar en su conjunto todos aquellos factores que aconsejan al Gobierno dictar la disposición impugnada (FJ 4 STC 182/1997), y entre ellos, de forma muy señalada, por ejemplo, el debate de convalidación de la norma. Del mismo es fácilmente deducible que el argumento fundamental fue la urgente necesidad de incen- 
tivar el consumo del sector del automóvil, ello justifica a criterio del TC, la apreciación de la extraordinaria y urgente necesidad de esa medida concreta a incluir en el decreto-ley. En relación con el segundo de los argumentos consistente en que mediante el decreto ley no se puede afectar al deber de contribuir por se una de los regulados en el Título I, el TC recuerda su doctrina de la STC 111/1983, de intentar lograr una posición equilibrada que evite las concepciones extremas, en cuya virtud se evite que el decreto-ley como figura normativa constitucionalmente diseñada quede reducida a la nada, ni que mediante la apelación al mismo sea regulado el régimen general de los derechos y libertades del título I (FJ 8 STC 111/1983; FJ 4 STC 60/1986; FJ 6 STC 182/1997). En conclusión, el decreto ley no puede alterar ni el régimen general ni los elementos esenciales del deber de contribuir", lo que exigirá precisar cómo se encuentra definido dicho deber en la Norma fundamental, concretamente en su art. 31.1; y es que, como señalamos en la STC 111/1983, comprobar cuándo el Decreto-ley 'afecta' a un derecho, deber o libertad 'exige también que se tenga muy en cuenta la configuración constitucional del derecho — en este caso, deber-afectado en cada caso' (FJ 8)". Como ya se precisó en la STC 182/1997, conforme a la propia literalidad del art. 31.1 CE el Decreto-ley no podrá alterar ni el régimen general ni aquellos elementos esenciales de los tributos que inciden en la determinación de la carga tributaria, afectando así al deber general de los ciudadanos de contribuir al sostenimiento de los gastos públicos de acuerdo con su riqueza mediante un sistema tributario justo. De manera que vulnerará el art. 86 CE cualquier intervención o innovación normativa que, por su entidad cualitativa o cuantitativa, altere sensiblemente la posición del obligado a contribuir según su capacidad económica en el conjunto del sistema tributario ( $F J 7$ ). A la luz de estas consideraciones procede concluir que al modificarse ese precepto tributario no se ha alterado de manera relevante la presión fiscal que deben soportar los contribuyentes por lo que se rechaza que se haya provocado un cambio sustancial en la posición de los ciudadanos en el conjunto del sistema tributario. Por lo que se refiere a la vulneración de la garantía procedimental, ya en el TC en la STC 16/2003, apuntó que el argumento central lo constituye el art. 46.1 EACan al establecer el núcleo básico de materias en relación con las cuales el Estado se ve en la necesidad de solicitar el informe previo al Parlamento, como allí se dijo este precepto cumple la función de configurar el supuesto de hecho de la norma jurídica contenida en la disposición adicional tercera de a Constitución. Ésta exige un determinado requisito, el informe previo autonómico, para producir válidamente el efecto jurídico que es la modificación del régimen económico y fiscal de Canarias, y el contenido de éste, para dar respuesta a la pregunta de cuándo es necesario tal informe, ha de ser definido precisamente en los términos establecidos en el Estatuto (FJ 6). En atención a las características del impuesto que se modifica -que grava el consumo-, a su incidencia en el conjunto del Régimen Económico y Fiscal de Canarias se considera obligado convenir que la modificación precisaba el informe o audiencia previos previstos en la DA Tercera CE y art. 46 EACan, conclusión que se refuerza argumentalmente si se tie- 
ne en cuenta que ésta fue la práctica tanto en el momento de creación de esta figura cuanto en el de las sucesivas modificaciones. No obstante esta declaración de inconstitucionalidad y nulidad del precepto en cuestión, en atención a las modificaciones que en el sistema de tributos cedidos se produce como consecuencia de la Ley 21/2001, el TC considera preciso modular el alcance de esa declaración de inconstitucionalidad para atender adecuadamente a otros valores con trascendencia constitucional, como los derechos de los terceros que adquirieron sus vehículos soportando una tributación menor a la que se produciría de haberse aplicado los tipos de gravamen anteriores a la reforma operada por el precepto anulado. Por este motivo, conforme a las exigencias del principio constitucional de seguridad jurídica (art. 9.3 CE), debemos afirmar que las situaciones jurídico-tributarias producidas a su amparo no son susceptibles de ser revisadas como consecuencia de la inconstitucionalidad que ahora declaramos.

\section{ORGANIZACIÓN TERRITORIAL DEL ESTADO}

\section{A. Comunidades Autónomas.}

\section{B.2. Competencias.}

1. Sentencia 109/2003, de 5 de junio (BOE de 1 de julio). Ponente: Vives Antón (Recursos de inconstitucionalidad acumulados).

Preceptos constitucionales: 33; 35; 36; 38; 149.1.1.1루 $149.1 .16^{\mathrm{a}}$.

otros:

Objeto: Ley 3/ 1996, de 25 de junio, de la Comunidad Autónoma de Extremadura, de atención farmacéutica; Ley 4/1996, de 26 de diciembre, de Castilla-La Mancha, de ordenación del servicio farmacéutico; Ley 16/1997, de 25 de abril, de regulación de los servicios de las oficinas de farmacia.

Materias: Derecho de propiedad; derecho al trabajo; colegios profesionales; libertad de empresa; condiciones básicas que garanticen la igualdad de los españoles; bases y coordinación general de la sanidad.

El principio de intransmisibilidad; la caducidad de las autorizaciones y la exclusión de la cotitularidad, son las tres cuestiones que se ponen a debate en relación con el régimen jurídico que las Comunidades Autónomas de Extremadura y Castilla-La Mancha han establecido en relación con la ordenación del servicio farmacéutica, así como en relación con la Ley del Estado 
16/1997, de regulación de los servicios de las oficinas de farmacia. Las oficinas de farmacia se configuran como establecimientos sanitarios. Desde el punto de vista competencial, ya la STC 32/1983 estableció que debe entenderse como una competencia de fijación de bases, que es, por tanto, en virtud del mandato del artículo 149.1.16, de titularidad estatal en cuanto trata de establecer características comunes en los centros, servicios y actividades de dichos centros. Tales requisitos y competencias deben considerarse como mínimos, cada Comunidad Autónoma podrá establecer medidas de desarrollo legislativo pudiendo añadir otros requisitos que entienda oportunos o especialmente adecuados (STC 80/1984). En materia de sanidad corresponde al Estado el establecimiento de la normativa básica. Y a las Comunidades Autónomas el desarrollo legislativo y la ejecución de dichas bases. Desde la exclusiva perspectiva de las normas estatales que deben ser consideradas básicas, se deben analizar, en primer lugar, los preceptos impugnados que se refieren al régimen de transmisibilidad de las oficinas de farmacia abiertas al público. La intransmisibilidad de las autorizaciones contenidas en la Ley de la Comunidad Autónoma Extremeña resulta claramente contraria a lo regulado en el art. 4 de la Ley 16/1997; en cuanto se impide cualquier clase de intransmisibilidad, el precepto 14 de dicha norma autonómica, debe ser declarado inconstitucional. Asimismo debe hacerse en relación con la DT Tercera en cuanto prevé que será posible la enajenación, cesión o traspaso por una sola vez, sin que sea posible el ejercicio del derecho de tanteo para la clausura del establecimiento. Por lo que se refiere al art. 18.1 de la Ley castellanomanchega en cuanto dispone que las autorizaciones administrativas para la instalación de nuevas oficinas serán intransferibles debe ser declarado inconstitucional; así mismo debe serlo la DT segunda al disponer la transmisibilidad tan sólo por una sola vez. Por lo que se refiere a la caducidad de las autorizaciones administrativas de aperturas de farmacia por cumplimiento de 70 años de edad, muerte, incapacitación o renuncia del titular de la autorización, es preciso señalar que el carácter personal de las autorizaciones de apertura de oficinas de farmacia no encaja sin dificultad con una transmisión enteramente libre; se debe partir de un principio de transmisibilidad limitada, las causas de caducidad sólo serían contrarias a las bases, si supusieran una enervación solapada de dicha transmisibilidad; el art. 14 de la Ley extremeña no conduce a semejante apreciación. Respecto de la caducidad por alcanzar la edad de 70 años, nada cabe objetar desde la perspectiva del 149.1.16 ; para alcanzar dicha conclusión sólo cabe recordar que el art. 149.1.1 $1^{\underline{a}}$ es un precepto que atribuye al Estado la competencia para regular las condiciones básicas que garanticen la igualdad de todos los españoles, lo que no es confundible con la identidad de las situaciones jurídicas de todos los ciudadanos (STC 37/1987). La doctrina de la STC 14/1998 debe entenderse aplicable en este caso, al no existir alteración alguna del régimen laboral que corresponde regular al Estado, sin que se aprecie vulneración de las reglas 6 y 7 del art. 149.1 CE. Por lo que se refiere a la caducidad de las autorizaciones por cumplimiento de 70 años de edad del far- 
macéutico y a la contratación de farmacéuticos adjuntos, se considera que no se produce vulneración del art. 149.1.16 $6^{\mathrm{a}}$ CE. Finalmente, por lo que se refiere a la norma castellano-manchega que sólo permite la titularidad de una oficina a un único farmacéutico, con exclusión de la cotitularidad, ha de ponerse de relieve que de la lectura del art. 4 de la Ley 16/1997-que tiene carácter básico se desprende con claridad que la transmisión de las oficinas de farmacia ha de poder realizarse en régimen de cotitularidad; por tanto, la previsión del precepto recurrido de que no pueda recaer cotitularidad resulta inconstitucional. La planificación farmacéutica es competencia autonómica lo que supone que no se encuentre tacha de inconstitucionalidad en la norma que exige la sola y única titularidad de una farmacia por cada farmacéutico. Acerca de la posibilidad de vulneración de los arts. 35, 36 y $38 \mathrm{CE}$, hay que comenzar diciendo, en relación con el primero de los citados, que el derecho al trabajo no se agota en la libertad de trabajar, sino que se concreta en el derecho a un puesto de trabajo en tanto se cumplan los requisitos de capacitación (STC 22/1981), sin que se aprecie la existencia de un contenido esencial constitucionalmente garantizado de cada profesión, oficio o actividad empresarial concreta; así como que el derecho constitucionalmente garantizado en el art. 35.1 CE no es el derecho a desarrollar cualquier actividad, sino el de elegir libremente profesión u oficio (FJ 3 STC 83/1984), de ahí que también se haya afirmado que la regulación del ejercicio profesional en cuanto no choque con otros preceptos constitucionales, puede ser hech a por el legislador en los términos que tenga por conveniente (FJ 3 STC 83/1984). Desde esta perspectiva, los supuestos de caducidad contemplados en las normas autonómicas no pueden ser calificados de inconstitucionales. Tampoco se aprecia vulneración del art. $33 \mathrm{CE}$ en la medida en que ya se ha declarado por el TC que la fijación del contenido esencial del derecho de propiedad privada...debe incluir igualmente la necesaria referencia a la función social entendida no como mero límite externo a su definición o a su ejercicio sino como parte integrante del derecho mismo (FJ 2 STC 37/1987). Ha de tenerse en cuenta asimismo la consideración de establecimientos sanitarios privados de interés público que corresponde a los establecimientos farmacéuticos, ambas consideraciones permiten concluir que la caducidad de la autorización en casos tasados y proporcionados no menoscaba el art. $33 \mathrm{CE}$ en la medida, además, en que queda garantizado el derecho de su titular a la libre disposición de los locales y enseres. Contiene el art. $36 \mathrm{CE}$ el mandato de que la Ley regule el ejercicio de las profesiones tituladas. Se entiende de aplicación la doctrina del ATC 158/1992, en cuya virtud no existe una relación directa entre el art. 36 y el desempeño de la titularidad de una oficina de farmacia, el cual permite el establecimiento de controles por parte de los poderes públicos; desde la óptica del art. 36 $\mathrm{CE}$ las causas de caducidad de las autorizaciones resultan irrelevantes. Finalmente ha de considerarse que no toda medida que incida en la libre circulación de bienes y personas es necesariamente contraria al art. 139.2 CE. (STC 37/1981); al tiempo, he de recordarse que la vigencia de la libertad de empresa no resulta constitucionalmente resquebrajada por el hecho de limitaciones de- 
rivadas de las reglas que disciplinen proporcionada y razonablemente el mercado (STC 127/1994). De acuerdo con esa doctrina las causas de caducidad cuestionadas no vulneran el art. $38 \mathrm{CE}$. En relación con la norma castellanomanchega de prohibir la titularidad de más de un establecimiento farmacéutico a la luz de los arts. 35, 36 y $38 \mathrm{CE}$, el TC sostiene que ni en su dimensión individual, ni en la colectiva se infringe el art. 35 CE. Por lo que se refiere al art. 36 en la medida en que no existe ninguna relación entre la titularidad de una única oficina de farmacia y el ejercicio de una profesión titulada, no puede apreciarse infracción del art. 36 CE. Por último, nada cabe oponer al principio de una única titularidad de oficina de farmacia, en atención al interés público vinculado a estas oficinas que justifica y exige la presencia de su titular. El TC considera, finalmente, que no es posible apreciar la conculcación del art. 149.1.1 CE.

VOTO PARTICULAR (García Manzano): Se disiente de la declaración de inconstitucionalidad de las normas autonómicas que se refieren a la prohibición de la transmisión de la autorización de oficinas de farmacia. Las normas autonómicas dictadas eran perfectamente respetuosas de las limitaciones entonces existentes en cuanto a la regulación a las que aquéllas se referían. La cuestión es consecuencia del ius superveniens, concretado en la promulgación de la Ley 16/1997. Se disiente de la consideración de básico de su art. 4.1. El único titulo competencial del Estado a tener en consideración es el que se refiere a las bases de la sanidad. Lo discutido en este pleito competencial atañe a la autorización administrativa de apertura y sus características y no a la condición de farmacéutico propietario que también reviste quien obtiene la autorización. No puede considerarse básico el contenido de un precepto que se refiere a un principio de transmisibilidad de la autorización. Debiendo, además, considerarse que las normas autonómicas guardan plena coherencia con el carácter intuitu personae de dichas autorizaciones, en atención al modo de acceso a ellas, teniendo en cuenta las condiciones de los aspirantes en términos de mérito y capacidad.

\section{Sentencia 123/2003, de 19 de junio (BOE de 7 de julio). Ponente: Vives An- tón (Recurso de inconstitucionalidad).}

Preceptos constitucionales: 149.1.22무 $149.1 .23^{\underline{a}}$.

otros:

Objeto: Determinados preceptos de la Ley 8/1995, de 27 de abril, de la Comunidad Autónoma de Extremadura, de pesca.

Materias: Recursos y aprovechamientos hidráulicos y legislación sobre el medio ambiente. 
Los preceptos impugnados vulneran el orden constitucional de competencias. El TC recuerda su doctrina sobre el régimen de los caudales circulantes en las cuencas supracomunitarias (SSTC 15/1998 y 110/1998) en torno al principio de unidad de gestión de la cuenca y el tratamiento homogéneo del recurso, en su virtud la especificación de los caudales mínimos y máximos circulantes corresponde en las cuencas hidrográficas que excedan el ámbito territorial de una Comunidad Autónoma, a los organismos de cuenca, entre cuyas funciones se encuentran la de administrar y controlar el dominio público hidráulico; ello impide una regulación independiente del mismo por cada una de las Comunidades Autónomas implicadas, no obstante el Organismo de cuenca determinará el régimen de los caudales ecológicos mediante la mutua colaboración con las CCAA. cuyo territorio forme parte parcial o totalmente de una cuenca hidrográfica. La determinación unilateral del citado régimen de caudales resulta contrario al reparto constitucional de competencias (STC 110/1998). Se reitera el criterio anterior del TC a tenor del cual la Ley autonómica se limita a disponer sin interferencia alguna en las competencias del Estado que sobre os concesionarios de aprovechamientos hidráulicos pesa la obligación de mantener ese caudal para salvaguardar el recurso piscícola objeto de pesca, cuya regulación le corresponde en virtud de la competencia exclusiva que ostenta sobre esa materia (STC 15/1998). En la medida en que el precepto en cuestión no atribuye a la Comunidad Autónoma la fijación del caudal mínimo se declara que no vulnera las competencias del Estado. En relación con el art. 27 se considera de aplicación la doctrina ya establecida en la STC 15/1998, a cuyo tenor, en la medida en que supone una intervención directa en el dominio público hidráulico con entero desconocimiento de la competencia estatal sobre el mismo; desplazamiento de competencias ajenas que no puede conducir, sino a la declaración de inconstitucionalidad del precepto. Por lo que se refiere al art. 28, se considera, asimismo, de aplicación lo ya establecido en la STC 15/1998, declarando que dicho precepto invade la competencia que al Estado reconoce el 149.1.23를 a igual conclusión se llega desde la perspectiva del 149.1.22 ${ }^{\mathrm{a}}$ por la que se atribuye al Estado la legislación, ordenación y concesión de recursos y aprovechamientos hidráulicos cuando las aguas discurran por más de una Comunidad Autónoma. Considera la Sentencia que en relación con el art. 29 no se produce en este caso infracción alguna del orden constitucional, en la medida en que la citada disposición no supone alteración alguna del régimen jurídico derivado de los pertinentes títulos concesionales cuyas condiciones corresponde determinar al organismo de cuenca, tratándose de una obligación adicional que el organismo de cuenca ha de tener presente a la hora de otorgar la oportuna concesión, según ya se declaró en las SSTC 243/1993; 15/1998; 110/1998. Para resolver la cuestión en relación con el art. 30 es de interés recordar lo que ya se dijo en la STC 15/1998, el citado precepto se limita a disponer una medida complementaria de protección del recurso pesquero que encuentra acomodo en la competencia de la Comunidad 
Autónoma para dictar normas adicionales de protección del medio ambiente, en definitiva, nos hallamos ante una medida complementaria de protección del ecosistema en el que habita la pesca respetuosa con cualquier autorización que pudieran dictar los organismos de cuenca en el ejercicio de sus funciones de policía. Sí infringe, por el contrario, el orden constitucional de competencias, el art. 31; en relación con el prácticamente idéntico art. 23.1 de la ley castallano-manchega ya se dijo que al disponer una prohibición general en relación con aquellos residuos que puedan perjudicar al recurso pesquero, pudieran generarse discrepancias acerca del alcance contaminante de determinadas sustancias, el precepto impugnado invade las competencias del Estado para dictar la legislación básica (SSTC 227/1988; 15/1998); a igual conclusión cabría llegar desde la perspectiva del art. 149.1.22a $\mathrm{CE}$. El art. 45.1 de la Ley extremeña es un precepto propio de la materia pesca fluvial en su dimensión conservacionista, destacándose, desde esta perspectiva, la finalidad prevalente de impedir métodos irregulares de pesca. No puede considerarse este precepto contrario a la Constitución. El art. 44.3 de la Ley extremeña no infringe las competencias del Estado al establecer la prohibición de navegar en zonas donde se entorpezca de forma notable la práctica de la pesca o se perturbe la tranquilidad de cualquier otra especie de fauna silvestre, es doctrina coincidente con la que ya se estableció en la STC 15/1998 en relación con las competencias de los organismos de cuenca (FJ 12), criterio que debe extenderse al inciso en el que las normas no son coincidentes por cuanto nada impide interpretarlo de conformidad con el bloque de la constitucionalidad, en la medida en que presupone la coordinación y la colaboración con el Estado, integrándose así las competencias hidráulicas y medioambientales tanto del Estado como de las Comunidades Autónomas. Por lo que se refiere a los preceptos que regulan las infracciones y sanciones conectadas a las cuestiones ya analizadas, el TC recuerda su doctrina de la STC 15/1998 (FJ 13) y 110/1998 (FJ 9), a tenor de la cual la competencia sustantiva justifica y legitima la potestad sancionadora, por lo que sólo aquellas infracciones tipificadas en la ley autonómica que interfieran en el ejercicio de las competencias estatales concurrentes serían merecedoras de un reproche de inconstitucionalidad (SSTC 15/1998, FJ 13; 110/1998, FJ $9)$. En la medida en que el régimen de caudales es competencia del organismo de cuenca sólo en relación con el art. 63.c).13 se produce la referida interferencia.

\section{Sentencia 124/2003, de 19 de junio (BOE de 17 de julio). Ponente: Pérez Vera (Recursos de inconstitucionalidad acumulados).}

Preceptos constitucionales: $81.1 ; 150.2 ; 149.1 .13^{\underline{a}}$

otros: 
Objeto: Ciertos preceptos de la Ley de ordenación del comercio minorista y de la LO complementaria de la de ordenación del comercio minorista.

Materias: Reserva de ley; planificación económica; leyes de transferencia o delegación; competencia sobre comercio interior.

Se cuestiona la competencia para la regulación de determinadas materias, así como la consideración de algunas como objetos de ley orgánica, no respetando la reserva de ley material que para éstas se establece en la CE. Por lo que se refiere a la primera de las cuestiones, en concreto es objeto de la pretensión las que lo tienen en los denominados grandes establecimientos. La primera cuestión consiste en determinar si al amparo del art. 149.1.13 el Estado puede dictar normas básicas sobre los establecimientos comerciales fijando una ordenación homogénea para todo el territorio; siendo la segunda si esta normativa básica puede imponer un informe del Tribunal de Defensa de la Competencia (TDC) como trámite preceptivo para otorgar o denegar aquella licencia. La primera cuestión debe ser resuelta acudiendo a las normas sobre distribución de competencia relativas a comercio interior. Éstas han sido asumidas por la Comunidad Foral, de acuerdo con las bases y la ordenación de la actividad económica general y de la política monetaria, crediticia, banacaria y de seguros del Estado. Se considera que esa normativa está contenida en parte de los preceptos impugnados, dictados al amparo del art. 149.1.13 ${ }^{\mathrm{a}}$ CE. Debe considerarse justificada la definición de gran establecimiento, siendo la finalidad de esta disposición adoptar una norma básica de ordenación económica respecto del sistema de distribución. El establecimiento de tales criterios respeta las competencias autonómicas. Por lo que se refiere al informe preceptivo y no vinculante del TDC, éste debe referirse a la existencia o no de un equipamiento comercial adecuado en la zona; enunciándose el segundo, como el efecto sobre la estructura comercial existente, teniendo en cuenta la mejora para la libre competencia... así como los efectos negativos que pudiera representar su existencia en la zona para el pequeño comercio preexistente. El segundo criterio justifica la necesidad del informe del TDC en la medida en que se pued ever afectado una ámbito supracomunitario; en los demás casos, la emisión del informe debe considerarse una facultad ejecutiva que corresponde a la Comunidad Autónoma, en atención a las consideraciones que ya se realizaron en la STC 208/1999. Por tanto, el inciso del art. 6.2 exigiendo informe preceptivo del TDC resulta constitucional si se entiende referido a las licencias comerciales específicas para grandes establecimientos cuando la instalación en la zona de que se trate pueda alterar la libre competencia en un ámbito supraautonómico. El segundo bloque de cuestiones se refiere a la impugnación de preceptos relativos a ventas de saldos, especiales, y ambulante y no sedentaria. Por lo que se refiere al primero de ellos, se considera amparado en la competencia exclusiva del Estado para regular el derecho mercantil de 
la competencia. Como ya ha declarado el Tc en diversas ocasiones (SSTC 62/1991; 88/1986; 228/1993), las CCAA son competentes para la emanación de regulaciones administrativas que disciplinen determinadas modalidades de venta, sin que ello suponga introducir una innovación en el seno de los derechos y obligaciones en el marco de las relaciones contractuales privadas. En la medida en que puedan verse afectado el régimen de competencia entre los ofertantes las normas correspondientes no tienen otro encaje competencial que el de la propia defensa de la competencia que corresponde al Estado. El título competencial esgrimido, sin embargo, no permite al Estado establecer una completa regulación sustantiva de Derecho Público de los supuestos excepcionados; en su articulación concreta, queda incluida de modo natural en las competencias de comercio interior y de protección del consumidor y del usuario que corresponden a la Comunidad Foral, si bien en este caso concreto el precepto impugnado no incurre en tal defecto. Por lo que se refiere a las ventas domiciliarias y a las ventas de saldos, la STC 88/1986 ya declaró que la práctica de ese tipo de venta corresponde al ámbito de disciplina del mercado que está atribuido a la competencia autonómica; al tiempo que, la necesidad de obtener un permiso para la venta es una cuestión de mera oportunidad o de politica administrativa correspondiente a la disciplina de mercado y dirigida a la protección del consumidor. La competencia estatal para dictar normas en materia de defensa del consumidor y del usuario, al amparo del 149.1.13 cluir cualquier acción de naturaleza económica si no posee una incidencia directa y significativa sobre la actividad económica general (STC 186/1988 y 133/1997), en caso contrario, se vaciaría de contenido una materia y un título competencial más específico. La exigencia de autorización y de su eventual inscripción registral para las ventas a distancia, ambulantes, automáticas o en pública subasta, no puede considerarse sino una medida de política administrativa correspondiente a la disciplina de mercado y dirigida a la protección del consumidor, por tanto, sin que pueda reputarse norma básica $e x$ art. 149.1.13 . Por lo que se refiere al precepto definidor del concepto de venta ambulante o no sedentaria, debe considerarse de aplicación general por ampararse en la competencia exclusiva del Estado para regular el contenido del derecho privado de los contratos. Las CCAA podrán regular, asimismo, determinados tipos de venta, en concreto la no sedentaria, siempre que dicha regulación se ciña al espacio de las relaciones jurídico públicas (STC 264/1993). En el caso sometido a la consideración del TC, la norma estatal se dirige a disciplinar la modalidad de venta ambulante en sus aspectos netamente públicos y por ello no puede entenderse amparada en el ámbito competencial reservado al Estado. El tercer bloque de cuestiones está directamente relacionado con el régimen de infracciones y sanciones. La regulación autonómica de esta materia está limitada por los principios básicos del ordenamiento estatal (STC 227/1988); el procedimiento sancionador habrá de ajustarse al administrativo común, de exclusiva competencia estatal, sin que ello implique que toda la regulación del derecho adminis- 
trativo sancionador sea competencia exclusiva del Estado (FJ ( STC $87 / 1985 ; 102 / 1995)$. En aplicación de estos criterios se ha declarado por el TC que el Estado tiene competencias para fijar unos principios que eviten divergencias irrazonables o desproporcionadas entre las distintas regulaciones autonómicas. El precepto impugnado establece un esquema básico al que ha de atenerse el ejercicio de la potestad sancionadora de la CCAA. Por lo que se refiere a los preceptos que regulan la reincidencia en las infracciones y su prescripción son encuadrables materialmente en el ámbito del art. 149.1.18 a , cuya configuración es de exclusiva competencia estatal. Por lo que se refiere a la impugnación en relación con los horarios comerciales, se considera que no es materia reservada a LO por lo que sería inconstitucional esa atribución de rango. Al respecto el TC recuerda su propia temprana doctrina a tenor de la cual si bien es cierto que existen materias reservadas a LLOO, no lo es menos que las LLOO están reservadas a estas materias y que, por tanto, sería disconforme con la CE que la LO invadiera materias reservadas a la Ley ordinaria (FJ 21 STC 5/1981). Ya la STC 225/1993 había señalado que en materia de régimen de horarios, el art. 38 no genera otra exigencia que la de que el mismo permita el inicio y el mantenimiento de la actividad empresarial, mas respetada esta exigencia, corresponde al ámbito de la libre configuración legal optar por un régimen limitativo de los horarios comerciales o por la libertad de horarios; dichos regímenes no forman parte del contenido de la libertad garantizada por el art. $38 \mathrm{CE}$. Se descarta, pues, que se pueda predicar el carácter orgánico del precepto enjuiciado por su eventual vinculación con el art. $38 \mathrm{CE}$. Haciendo aplicación de la doctrina de la STC 5/1981, la 76/1983 ha declarado que la LO puede contener preceptos no orgánicos relativos a materias conexas, debiendo preciar el legislador cuáles sean éstos. La presencia de un precepto orgánico en una Ley no atribuye tal carácter a la totalidad de la misma, para que ello ocurra, es preciso ante todo que el núcleo de la Ley afecte a materias reservadas a la LO de acuerdo con las previsiones del art. 81.1 CE. La LO sólo puede incluir preceptos que excedan del ámbito estricto de la reserva cuando su contenido desarrolle el núcleo orgánico y siempre que constituyan un complemento necesario para su mejor inteligencia. En los supuestos en que se mezclen normas orgánicas y otras que no tengan tal carácter, el legislador habrá de concretar cuáles sean los preceptos que sí lo tienen. Los preceptos cuestionados no pueden ser considerados orgánicos en la medida en que no puede entenderse que mediante ellos se transfiera facultad alguna en materia de comercio interior. La inclusión de estos preceptos en la LO sólo podría obedecer a una conexión temática lo que es difícil de predicar en relación con el art. 1; el legislador debió declarar el carácter no orgánico de los arts. 2 y 3 y, al no hacerlo, lo hace ahora el TC.

VOTO PARTICULAR (Rodríguez-Zapata Pérez al que se adhiere GarcíaCalvo y Montiel): Se centra la disidencia en la naturaleza de las LLOO del art. 150.2 CE, por entender que se debió rechazar el recurso bien por pér- 
dida de objeto, bien por apreciar la constitucionalidad de la Ley en una interpretación conforme. No se puede afrontar el problema que aquí se plantea sin una reflexión del contenido y alcance del art. $150 \mathrm{CE}$, en cuyo párrafo 2 se contemplan las leyes orgánicas de transferencia, en su carácter de herramienta dúctil e imprescindible para nuestro proceso autonómico. La Sentencia de la que se disiente niega el carácter de ley orgánica a la norma objeto de la cuestión debatida. Admitido el carácter básico relativo a la libertad de horarios comerciales, resulta coherente defender el carácter de ley orgánica de transferencia a la Ley objeto de la cuestión que se debate. No se ha tenido en cuenta que, entre las leyes orgánicas, las de transferencias son una categoría específica, un tipo especial en el que el elemento formal predomina sobre el substancial o material, que dicha competencia de naturaleza normativa junto a otras de carácter simplemente ejecutivo, eran susceptibles de ser transferidas por el Estado o, lo que es lo mismo, cedidas al amparo del art. 150.2 CE a las CCAA. El carácter orgánico de la ley cuestionada proviene de su propia función y finalidad que no parece otra que la de arbitrar un instrumento legislativo que permitiera de un lado poner coto al desorden reinante en materia de horarios comerciales al tiempo que proporcionar un marco legislativo que recondujera unitariamente dicha situación competencial, lo que únicamente resultaba posible al amparo del art. 150.2 CE. Estamos ante una ley orgánica de transferencia que no tiene por objeto regular sustantivamente competencias estatales sobre una materia. Partiendo del principio de libertad de horarios lo sujeta a un enmarañado régimen transitorio en el que se asienta el cuadro de la transferencia . Lo enmarañado de su contenido no puede afectar a la corrección técnica del medio empleado y no puede provocar su inconstitucionalidad. En definitiva, mediante los debatidos arts. 2 y 3 se opera una transferencia de competencias que producen efectos diversos dependiendo de la situación competencial asumida por cada Comunidad Autónoma, siendo este modo de actuar el único viable para introducir cierto orden en la confusión existente. La extensión del límite de las materias reservadas a la generalidad de las leyes orgánicas, a tipos de leyes orgánicas como los EEAA o las leyes de transferencias se hace en la sentencia de la que se discrepa de forma apresurada. 